\title{
Prevalence and determinants of post-- abortion family planning utilization in a tertiary Hospital of Northwest Ethiopia: a cross sectional study
}

\author{
Enyew Abate ${ }^{1 *}\left(\mathbb{D}\right.$, Yolanda R. Smith², Walelign Kindie ${ }^{1}$, Addisu Girma $^{3}$ and Yonas Girma ${ }^{4}$
}

\begin{abstract}
Background: Provision of post abortion contraception following an abortion is an excellent opportunity to address unmet family planning needs of women. In Ethiopia, post abortion family planning is minimal and underutilized. The objective of this study is to assess determinant factors for utilization of contraception following any abortion process (induced and/or spontaneous) among reproductive age women (15-49 years) in a tertiary hospital of North West Ethiopia.

Methods: A cross-sectional study was conducted on 423 clients who presented for either spontaneous or induced abortion care from September 2016 to August 2017 in Felege Hiwot referral hospital, North West Ethiopia. Respondents were identified using a consecutive sampling method. Data was collected in clinic using an interviewer administered pre-tested questionnaire administered after services were completed. Factors associated with use of post-abortion family planning were explored using multivariable logistic regression analysis.

Results: $64.8 \%$ of clients who presented for abortion care received family planning services before discharge from the hospital. Family planning counseling during service provision [AOR: 25.47, 95\% Cl: $(9.11,71.58)]$, having previous information about family planning [AOR: $2.16,95 \% \mathrm{Cl}:(1.09,4.23)]$, gestational age of index pregnancy less than 3 months [AOR: $1.78,95 \% \mathrm{Cl}:(1.13,3.05)]$, being a housewife [AOR: $0.32,95 \% \mathrm{Cl}:(0.16,0.65)]$ and monthly income > 5000 ETB [AOR: $0.38,95 \%$ Cl:(0.16,0.98)] are significantly associated with post abortion family planning utilization.

Conclusions: The proportion of post abortion family planning utilization is good but could be improved. Education before and especially at the time of abortion services strongly influenced the usage of family planning services. The government and regional health bureau at large as well as health care providers at each health system level have an opportunity to provide information and counsel women on family planning methods to increase utilization of post abortion contraception.
\end{abstract}

Keywords: Post abortion family planning, Abortion services, Bahir Dar, Ethiopia

\footnotetext{
*Correspondence: enyewabate@gmail.com

${ }^{1}$ College of Medicine and Health Sciences, Department of Obstetrics and

Gynecology, Bahir Dar University, Bahir Dar, Ethiopia

Full list of author information is available at the end of the article
}

\section{$\triangle B M C$}

(c) The Author(s). 2020 Open Access This article is licensed under a Creative Commons Attribution 4.0 International License, which permits use, sharing, adaptation, distribution and reproduction in any medium or format, as long as you give appropriate credit to the original author(s) and the source, provide a link to the Creative Commons licence, and indicate if changes were made. The images or other third party material in this article are included in the article's Creative Commons licence, unless indicated otherwise in a credit line to the material. If material is not included in the article's Creative Commons licence and your intended use is not permitted by statutory regulation or exceeds the permitted use, you will need to obtain permission directly from the copyright holder. To view a copy of this licence, visit http://creativecommons.org/licenses/by/4.0/ The Creative Commons Public Domain Dedication waiver (http://creativecommons.org/publicdomain/zero/1.0/) applies to the data made available in this article, unless otherwise stated in a credit line to the data. 


\section{Background}

The World Health Organization (WHO) estimates that abortion related complications are responsible for the deaths of approximately 800,000 women each year worldwide, which accounts for $19.6 \%$ of all maternal deaths $[1,2]$.

Ethiopia has one of the world's highest maternal mortality ratios, 412 per 100,000 live births [3]. In Ethiopia, $38 \%$ of pregnancies are unintended, with an estimated 620,300 induced abortions performed each year. Among these pregnancy terminations, $53 \%$ occur in health facilities and $47 \%$ are performed outside of health facilities [4].

Family planning is a successful strategy to address this issue, and overall prevents $32 \%$ of maternal deaths from all causes [5]. Post abortion family planning is family planning that is provided to clients or individuals after a spontaneous or an induced abortion [6]. This post abortion period is a time when women are highly motivated to avoid or delay another pregnancy $[7,8]$. This provides an opportunity to offer services immediately after the provision of abortion care.

Most unwanted pregnancies in developing countries occur as a result of restricted access to family planning services $[9,10]$. In Ethiopia, 22\% of women have an unmet need for family planning [3]. Providing voluntary post abortion family planning options generally reduces subsequent unintended pregnancies and further decreases maternal mortality $[1,6]$. A consensus statement developed by Post Abortion Care Consortium and International Conference on Population and Development (ICPD) stated that the pregnancy-abortion-pregnancy cycle must be broken by providing post-abortion contraception to those who are in need of it [11].

Multiple studies done in Asia, South America and Africa on post-abortion family planning utilization showed wide variations in use, ranging from 61 to $97 \%$ [10, 12, 13]. A cross-sectional study performed in three health facility based settings in Ethiopia demonstrated that 48$59 \%$ of clients left their institution with post-abortion family planning services which showed wide variations in the percentage of women who received post-abortion contraception [14-16]. In addition, comparative studies from countries outside Ethiopia reveal a greater acceptance and use of modern contraceptives in women who received post abortion family planning counseling and services relative to the no-program group [17-19].

Several factors are associated with women's decisions regarding starting post-abortion family planning. Studies done in Ethiopia indicate that urban residence, higher maternal education level, occupation, undergoing spontaneous abortion, receiving post abortion family planning counseling, good knowledge of family planning, and availability of family planning are significantly associated with uptake of family planning in the postabortion period [16, 20-24].

Research performed around the world shows variation in the utilization of post-abortion family planning and type of methods offered and identified determinant factors. The majority of the research done in Ethiopia is community based and or health facility based studies.

No identified Ethiopian studies have sampled patients only from a tertiary teaching hospital to assess family planning utilization following abortion, where more complicated cases of abortion and women with advanced gestational age will come and where medical training occurs which may reflect what happens to the community after trainees leave.

Therefore, this study was done to provide information on the proportion and determinant factors for utilization of post abortion contraception in a tertiary teaching hospital in Ethiopia.

\section{Methods and materials \\ Study setting, design and population}

The study was an institutional cross-sectional study using quantitative data collection methods. It was conducted at Felege Hiwot referral hospital (FHRH), Bahir Dar, northwest Ethiopia from September 1, 2016 to August 31, 2017. FHRH is comprehensive specialized referral and teaching hospital found in Bahir Dar city, the capital of Amhara regional state which is located 563 $\mathrm{Km}$ away from the capital city Addis Ababa. It serves as referral hospital for South Gondar, East and West Gojjam, Awi zone and Benshangul Gumuz region providing service for about nine million populations.

We included all women who came for abortion care to get abortion services from FHRH. The sample size was calculated with the single population proportion formula: using 95\% CL, 5\% marginal error [25]. Using data on proportion of post-abortion family planning utilization done in Dessie, North East Ethiopia, which was $47.5 \%$ [15] and adding a $10 \%$ non-response rate, the planned sample size was 423 .

\section{Data collection}

Women were approached sequentially by trained bachelor degree holder nurses after their clinical visit was completed and while preparing to leave the hospital, until the desired sample size was achieved. Women who consented to participate completed a semi-structured interviewer administered questionnaire with 24 questions. The questionnaire was initially prepared in English and translated to Amharic language on a printout paper. The questions covered socio demographic characteristics, reproductive performance, previous abortion history, previous knowledge and utilization of any contraceptive methods, interest in future fertility, 
current pregnancy and abortion related circumstances which were obtained from the clients and health care provider information which was obtained from the abortion registration logbook.

\section{Data analysis}

Data was entered and cleaned using Epi-data version 3.1, independently verified, exported and analysis was done using SPSS Version 22.0.

Descriptive statistics were used to assess the percentage of individual client characteristics and percentage of utilization of post-abortion family planning.

Bivariable analyses were performed, examining the association of selected independent variables with the outcome of post-abortion family planning utilization. Predictors with $p$ values less than 0.25 were entered into subsequent multivariable models employing forward selection approach. The final multivariable logistic regression modelling was built by including predictors with $\mathrm{p}$ value less than 0.05 was undertaken to evaluate the net effects of set of predictor variables over the utilization of post abortion family planning.

\section{Results}

\section{Sociodemographic characteristics}

A total of 423 post abortion women participated in the study. Among the study participants, the majority of women were in the age group between 25 and 29 years (33.3\%), resided in urban areas $(58.9 \%)$, married $(74 \%)$ and had access to at least one communication media (86.1\%) (Table 1).

\section{Obstetric and contraceptive history}

Among the women participants, most of them had no child, had no previous abortion and wanted to be pregnant with in the next 6 months following the abortion process. Two thirds of women had spontaneous abortion and for majority abortion was done and/or completed by male nurses or midwives by using surgical methods. Most of the study participants had received counseling on family planning (Table 2 ).

\section{Utilization of post abortion contraception}

Of all the study participants, nearly two third (274, $64.8 \%)$ had left the hospital after they have received family planning service. A little more than one third of women $(35.2 \%)$ didn't receive any type of family planning and among them, $30 \%$ of women said nobody discussed the issue of contraception and another one third (30\%) said they wanted to be pregnant in the near future.

Among women who received post abortion family planning services, majority (82.5\%) had received upon discharge to their home and only $17.5 \%$ received services immediately
Table 1 Sociodemographic characteristics of study participants in Felege Hiwot referral hospital from Sep 2016- Aug 2017

\begin{tabular}{|c|c|c|}
\hline \multirow[t]{2}{*}{ Characteristics } & \multicolumn{2}{|l|}{ Total } \\
\hline & Number & Percent \%) \\
\hline \multicolumn{3}{|l|}{ Age in years } \\
\hline Less than 19 & 62 & 14.7 \\
\hline $20-24$ & 111 & 26.2 \\
\hline $25-29$ & 141 & 33.3 \\
\hline $30-34$ & 63 & 14.9 \\
\hline$>35$ & 46 & 10.9 \\
\hline \multicolumn{3}{|l|}{ Place of residence } \\
\hline Urban & 249 & 58.9 \\
\hline Rural & 174 & 41.1 \\
\hline \multicolumn{3}{|c|}{ Current marital status } \\
\hline Married & 313 & 74 \\
\hline Not married & 110 & 26 \\
\hline \multicolumn{3}{|l|}{ Religion } \\
\hline Orthodox & 361 & 85.3 \\
\hline Islam & 57 & 13.5 \\
\hline Others & 5 & 1.2 \\
\hline \multicolumn{3}{|l|}{ Educational status } \\
\hline illiterate & 162 & 38.3 \\
\hline Primary school & 83 & 19.6 \\
\hline Secondary school & 95 & 22.5 \\
\hline Higher education & 83 & 19.6 \\
\hline \multicolumn{3}{|l|}{ Occupation } \\
\hline Employed & 117 & 27.7 \\
\hline Student & 71 & 16.8 \\
\hline House wife & 132 & 31.2 \\
\hline Daily laborer & 27 & 6.4 \\
\hline Farmer & 76 & 17.9 \\
\hline \multicolumn{3}{|c|}{ Monthly income in birr ${ }^{a}$} \\
\hline$<5000$ & 372 & 87.9 \\
\hline$\geq 5000$ & 51 & 12.1 \\
\hline \multicolumn{3}{|c|}{ Availability of communication media } \\
\hline Yes & 364 & 86.1 \\
\hline No & 59 & 13.9 \\
\hline
\end{tabular}

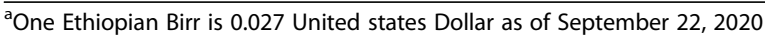

after treatment. From the different contraceptives given to those women, Depo Provera injectable contraception was the most chosen method $(138,50 \%)$ and the least chosen method was traditional method $(6,2 \%)$.

\section{Factors associated with post abortion contraceptive utilization}

The result of the Bivariate and Multivariable logistic regression analysis is displayed in Table 3. The Adjusted 
Table 2 Description of obstetrics, contraceptive and abortion related factors of study participants in Felege Hiwot referral hospital from Sep 2016- Aug 2017

\begin{tabular}{|c|c|c|}
\hline \multirow[t]{2}{*}{ Characteristics } & \multicolumn{2}{|l|}{ Total } \\
\hline & Number & Percent (\%) \\
\hline \multicolumn{3}{|l|}{ Number of alive children } \\
\hline None & 217 & 51.3 \\
\hline One to four & 170 & 40.2 \\
\hline$\geq$ five & 36 & 8.5 \\
\hline \multicolumn{3}{|l|}{ Need for near future pregnancy } \\
\hline Yes & 200 & 47.3 \\
\hline No & 223 & 52.7 \\
\hline \multicolumn{3}{|l|}{ Previous history of abortion } \\
\hline Yes & 86 & 20.3 \\
\hline No & 337 & 79.7 \\
\hline \multicolumn{3}{|c|}{ Previous history of abortion care service } \\
\hline Yes & 60 & 14.2 \\
\hline No & 363 & 85.8 \\
\hline \multicolumn{3}{|l|}{ Previous information about FP } \\
\hline Yes & 345 & 81.6 \\
\hline No & 78 & 18.4 \\
\hline \multicolumn{3}{|l|}{ Currently counseled on FP } \\
\hline Yes & 380 & 89.8 \\
\hline No & 43 & 10.2 \\
\hline \multicolumn{3}{|l|}{ Pregnancy planned } \\
\hline Yes (Planned) & 225 & 53.2 \\
\hline No (Unplanned) & 198 & 46.8 \\
\hline \multicolumn{3}{|l|}{ Pregnancy wanted and supported } \\
\hline Yes (Wanted and supported) & 290 & 68.6 \\
\hline No (Unwanted and unsupported) & 133 & 31.4 \\
\hline \multicolumn{3}{|c|}{ Gestational age of current pregnancy } \\
\hline Less than three months & 185 & 43.7 \\
\hline Three to seven months & 238 & 56.3 \\
\hline \multicolumn{3}{|l|}{ Type of current abortion } \\
\hline Spontaneous & 292 & 69 \\
\hline Induced & 131 & 31 \\
\hline \multicolumn{3}{|l|}{ Type of abortion procedure } \\
\hline Medication abortion & 115 & 27.2 \\
\hline MVA & 242 & 57.2 \\
\hline Both & 66 & 15.6 \\
\hline \multicolumn{3}{|l|}{ Sex of service provider } \\
\hline Male & 349 & 82.5 \\
\hline Female & 74 & 17.5 \\
\hline \multicolumn{3}{|l|}{ Profession of service provider } \\
\hline Nurse or midwifery & 279 & 66 \\
\hline General practitioner and above & 144 & 34.1 \\
\hline
\end{tabular}

Odds Ratio (AOR) revealed that receiving family planning counseling during service provision $(25.47$ [95\% CI: $9.11,71.58])$, occupation of the patient $(0.32[95 \% \mathrm{CI}$ : $0.16,0.65]$ ), having previous information about family planning (2.16 [95\% CI: 1.09, 4.23]), gestational age of current pregnancy $(1.78[95 \%$ CI: 1.13, 3.05]) and monthly income of the family $(0.38[95 \% \mathrm{CI}: 0.16,0.98])$ have a significant impact on the utilization of post abortion family planning. Particularly, among Sociodemographic characteristics, women who are house wife were twenty times less likely to utilize PAFP. Similarly, the odds of using of PAFP in women whose monthly income was 5000 Ethiopian birr (ETB) and above were thirtyeight times less likely than their counter parts.

The odds of utilization of post abortion family planning by women who received family planning counseling during service provision was 25.47 times than those women who didn't. Likewise, the odds of using PAFP in women who have previous information about family planning was 2.16 times to those women who didn't have previous information. Similarly, the odds of using PAFP in women whose current gestational age of pregnancy was less than 3 months was 1.78 times those whose gestational age was 3 to 7 months.

\section{Discussion}

This cross-sectional study was conducted to assess the utilization of post-abortion family planning and associated factors in women who receive abortion care service. Accordingly, the proportion of use of post abortion family planning in this study was $64.8 \%$. When compared with the studies done in Dessie (47.5\%), Debre Markos (59.2\%) and Gurage (56.5\%), it is higher [14-16]. The possible explanations for these could be differences in study set up and time difference. In Dessie and Debre Markos studies, the study was performed in public, private and Non-Government Organization (NGO) clinics and in Gurage; they studied utilization in facilities at all levels of health system, whereas the current study was done in tertiary hospital. However, the studies done in Mexico (82\%) and Brazil (97\%), both had utilization above our study $[10,12]$. This might be as result of different study design and set up. In Brazilian study they used a cohort study [10]. Another explanation might be excellent quality of service and health service coverage. On the other hand, our results are comparable with other studies done in Ghana (65\%) and Burkina Faso (65.7\%) [19, 26].

Client occupation is one factor which was identified to be associated with PAFP. On the contrary, in prior studies in Dessie [15] and Debre Markos [16] occupation had no statistically significant association with utilization of post abortion family planning. Our study found that women who are housewives were less likely to utilize 
Table 3 Factors associated with utilization of post abortion contraception, logistic regression analysis, Felege Hiwot referral hospital, Ethiopia, from Sep 2016- Aug 2017

\begin{tabular}{|c|c|c|c|}
\hline Variables & COR (95\%) & AOR (95\%) & AOR $P$-value \\
\hline \multicolumn{4}{|l|}{ Occupation } \\
\hline Employed & 1 & 1 & \\
\hline House wife & $1.10(0.78,1.54)$ & $0.32(0.16,0.65)$ & .002 \\
\hline \multicolumn{4}{|l|}{ Monthly income in birr } \\
\hline$<5000$ & 1 & 1 & \\
\hline$\geq 5000$ & $1.41(0.51,2.31)$ & $0.38(0.16,0.98)$ & .037 \\
\hline \multicolumn{4}{|c|}{ Previous information about FP } \\
\hline Yes & $2.05(1.64,2.57)$ & $2.16(1.09,4.23)$ & .028 \\
\hline No & 1 & 1 & \\
\hline \multicolumn{4}{|l|}{ Currently counseled on FP } \\
\hline Yes & $2.59(2.07,3.24)$ & $25.47(9.11,71.58)$ & $<.001$ \\
\hline No & 1 & 1 & \\
\hline \multicolumn{4}{|c|}{ Gestational age of current pregnancy } \\
\hline Less than three months & $2.36(1.72,3.24)$ & $1.78(1.13,3.05)$ & .038 \\
\hline Three to seven months & 1 & 1 & \\
\hline
\end{tabular}

PAFP. The possible reason could be that housewives have more time and support at home to raise a child, while women who are employed may intend to delay pregnancy.

Women whose monthly income was 5000 ETB and above were less likely to use PAFP than those women whose monthly income was less than 5000 ETB. This is contrary to another Ethiopian study from Addis Ababa, which found no significant association between use of post-abortion contraception and monthly income of the client [23].

Respondents who have previous information about family planning and those who were provided with post abortion family planning counseling were more likely to use PAFP than those who did not have previous information and were not counseled. These results are similar to those from other studies done in Debre Markos, Kenya and Turkey $[1,16]$. This emphasizes the impact that post-abortion family planning counseling has on utilization of post abortion family planning.

Clients whose gestational age is less than 3 months in the current pregnancy were more likely to use post abortion family planning than those whose gestational age is 3 to 7 months. However, the studies from Dessie and Addis Ababa did not find a similar association [15, 20]. One possible explanation may be that our second trimester abortions have included women who had an induced abortion for medical reason following planned pregnancy. Therefore, these women may not wish to delay another pregnancy following the abortion process.

This was a single site study done in a referral hospital where generalization could be compromised as single hospital will not represent the community. The study also may not give the real utilization of post abortion family planning service because perhaps clients might show courtesy bias during the exit interview even if they were assured that all their words will be kept confidential.

\section{Conclusions and recommendations}

In this study post-abortion contraceptive prevalence in a tertiary hospital was low as compared with studies done outside the country, even if it is higher than studies done in our country. Still there is more to be done to increase post-abortion contraception utilization. Family planning counseling during service provision, being a housewife, having previous information about family planning, monthly income and gestational age of index pregnancy are significantly associated with post-abortion family planning utilization. The type of abortion, miscarriage or induced, did not impact the interest and acceptance of contraception. We strongly recommend the government and regional health bureau at large and health care providers at each health system level in particular to provide family planning counseling for those women who come for any type of abortion related service.

\section{Abbreviations}

AIDS: Acquired Immune Deficiency Syndrome; ARHB: Amhara Regional Health Bureau; CIRHT: Centers for International Reproductive Health Training; EDHS: Ethiopian Demographic Health Survey; ETB: Ethiopian birr; FHRH: Felege Hiwot Referral Hospital; HIV: Human Immune Virus; ICPD: International Conference on Population and Development; IUCD: Intra Uterine Contraceptive Device; MVA: Manual Vacuum Aspiration; PAFP: Post Abortion Family Planning; WHO: World Health Organization 


\section{Acknowledgments}

We would like to express our gratitude to Pre-Publication Support Service (PREPSS) for pre-publication peer review and copy editing of the manuscript. Authors are very grateful for the funding provided by CIRHT and training of the authors at each step of the study. We would like to thank the study participants too.

\section{Authors' contributions}

EA contributed in the proposal write up, data analysis and manuscript writing. WK and AG involved in proposal development and write up. YRS and YG involved in commenting data analysis and manuscript writing. All authors read and approved the final manuscript for submission.

\section{Funding}

The funding is provided by CIRHT to conduct the study with full support.

\section{Availability of data and materials}

All generated data are included in the manuscript.

\section{Ethics approval and consent to participate}

Ethical clearance was obtained from the ethics review committee of the Bahir Dar University. Permission was obtained from the Amhara national regional health bureau and medical director of Felege Hiwot Referral Hospital. Data collection was conducted after explaining the purpose of the study to the participants and a verbal consent was obtained from each participant after explaining their right not to answer any of the questions and terminate the interview if they are not comfortable.

\section{Consent for publication}

Not applicable for this study.

\section{Competing interests}

The authors declare that they have no competing interests.

\section{Author details}

${ }^{1}$ College of Medicine and Health Sciences, Department of Obstetrics and Gynecology, Bahir Dar University, Bahir Dar, Ethiopia. ${ }^{2}$ Department of Obstetrics and Gynecology, University of Michigan and Centers for International Reproductive Health Training (CIRHT), Ann Arbor, Michigan, USA. ${ }^{3}$ Debre Birhan Referral Hospital, Debre Birhan, Ethiopia. ${ }^{4}$ Centers for International Reproductive Health Training (CIRHT), Addis Ababa, Ethiopia.

Received: 25 September 2019 Accepted: 8 December 2020 Published online: 14 December 2020

\section{References}

1. Ceylan A, Ertem M, Saka G, Akdeniz N. Post abortion family planning counseling as a tool to increase contraception use. BMC Public Health. 2009;9(20). https://doi.org/10.1186/1471-2458-9-20.

2. Tessema G, Laurence C, Melaku Y, Misganaw A, Woldie SA, Hiruye A, et al. Trends and causes of maternal mortality in Ethiopia during 1990-2013: findings from the global burden of diseases study 2013. BMC Public Health. 2017. https://doi.org/10.1186/s12889-017-4071-8.

3. Ethiopian stastical agency, Ethiopian democratic health survey. 2016 Available at < https://datacatalog.worldbank.org/dataset/ethiopiademographic-and-health-survey-2016-0>.

4. Moore A, Gebrehiwot Y, Fetters T, Bado Y, Bankole A, Singh S, et al. The estimated incidence of induced abortion in ethiopia,2014: changes in the provision of services since 2008. Int Perspect Sex Reprod Health. 2016;42(3): $111-20$

5. Minstry Of Health of Ethiopia, National Guideline for Family Planning Services in Ethiopia. 2011: Available at https://www.scirp.org/reference/ ReferencesPapers.aspx? ReferencelD=1317212>.

6. Guttmacher Institute. Facts on Induced Abortion Worldwide. Geneva, Switzerland. 2007. Available at < https://www.guttmacher.org/fact-sheet/ induced-abortion-worldwide>.

7. FIGO, Post abortion family planning:a key component of post abortion care. 2013. Available at <https:/www.figo.org/news/post-abortion-familyplanning-key-component-post-abortion-care-0014665>.
8. Gizaw A, Regassa N. Family planning service utilization in mojo town, Ethiopia: a population based study. J Geography Regional Planning. 2011; 4(6):355-63.

9. Sedgh $\mathrm{G}$, Singh $\mathrm{S}$, Hussain R. Intended and unintended pregnancies worldwide in 2012 and recent trends. Stud Fam Plan. 2014;45(3):301-14.

10. Ferreira A, Souza A, Lima R, Braga C. Choices on contraceptive methods in post-abortion family planning clinic in the northeast Brazill. Reprod Health J. 2010;7(5) http://www.reproductive-health-journal.com/content/7/1/5.

11. International Conference on Population and Development. Post abortion Care Consortium. Cairo; 1994. Available at < https://www.ncbi.nlm.nih.gov/ books/NBK138200/ >.

12. Becker D, Olavarrieta C, Garcia S, Harper C. Women's reports on postabortion family-planning services provided by the public-sector legal abortion program in Mexico City. Int J Gynaecol Obstet. 2013;121(2):149-53.

13. Azmat S, Hameed S, Ishaque M, Mustafa G. Post-abortion care family planning use in Pakistan. Pakistan J Public Health. 2012;2(2):4-9.

14. Tesfaye G, Oljira L: Post abortion care quality status in health facilities of Guraghe zone, Ethiopia. Bio med central reproductive health, 2013. http:// www.reproductive-health-journal.com/content/10/1/35

15. Seid A, Gebremariam A, Abera M. Integration of family planning services within post abortion Care at Health Facilities in Dessie -north East Ethiopia. Sci Technol Arts Res J. 2012:1(1):38-46.

16. Kokeb L, Admassu E, Kassa H, Seyoum T. Utilization of Post Abortion Contraceptive and Associated Factors among Women who Came for Abortion Service: a Hospital Based Cross Sectional Study. J Fam Med Disease Prev. 2015;1:022.

17. Tripney J, Kwan I, Schucan Bird K. Postabortion family planning counseling and services for women in low-income countries: a systematic review. Contraception. 2013;87(1):17-25. https://doi.org/10.1016/j.contraception. 2012.07.014.

18. Khanal V, Joshi C, Neupane D, Karkee R. Practices and percepions on contraception acceptance among clients availing safe abortion services in Nepal. Kathmandu Univ Med J. 2011;35(3):179-84. https://doi.org/10.3126/ kumj.v9i3.6301.

19. Kiemtoré S, Zamane H, Sawadogo YA, Ouédraogo CM, Kaïn DP, Diallo A et al. Integration of post abortion care package in the activity of 56 health facilities by the Burkina Faso Society of Obstetricians and Gynecologists. Open J Obstetr Gynecol. 2016;6:457-62.

20. Prata N, Bell S, Holston M, Gerdts C, Melkamu Y. Factors associated with choice of post-abortion contraception in Addis Ababa, Ethiopia. Afr J Reprod Health. 2011;15(3):51.

21. Amentie M, Abera M, Abdulahi M. Utilization of family planning services and influencing factors among women of child bearing age in assosa district, benishangul gumuz regional state, West Ethiopia. Sci J Clin Med. 2015;4(3): 52-9.

22. Assefa $\mathrm{H}$, Fikrewold $\mathrm{H}$. Factors affecting unmet need for family planning in southern nations, nationalities and peoples region, Ethiopia. Ethiop J Health Sci. 2011:21(2):77-89.

23. Zemene A, Feleke A, Alemu A, Yitayih G, Fantahun A. Factors Influencing Utilization of Post Abortion Care in Selected Governmental Health Institutions, Addis Ababa, Ethiopia. Fam Med Med Sci Res. 2014;3(115). https://doi.org/10.4172/2327-72.1000115.

24. Abamecha A, Shiferaw A, Kassaye A. Assessment of post abortion contraceptive intention and associated factors among abortion clients in gambella health facilities, gambella town, south West Ethiopia. Int J Med Sci Clin Inventions. 2016;3(8):2061-70.

25. DH., S. Statistics: A first course, ed. t. edition. New York: McGraw Hill; 1995.

26. Maxwell L, Voetagbe G, Paul M, Mark A. Does the type of abortion provider influence contraceptive uptake after abortion? An analysis of longitudinal data from 64 health facilities in Ghana. BMC Public Health. 2015;15:586. https://doi.org/10.1186/s12889-015-1875-2.

\section{Publisher's Note}

Springer Nature remains neutral with regard to jurisdictional claims in published maps and institutional affiliations. 